\title{
Vectorial analysis of dielectric photonic crystal VCSEL
}

\author{
Chung, II-Sug; Mørk, Jesper
}

Published in:

11th International Conference on Transparent Optical Networks, 2009. ICTON '09

Link to article, DOI:

10.1109/ICTON.2009.5185025

Publication date:

2009

Document Version

Publisher's PDF, also known as Version of record

Link back to DTU Orbit

Citation (APA):

Chung, I-S., \& Mørk, J. (2009). Vectorial analysis of dielectric photonic crystal VCSEL. In 11th International Conference on Transparent Optical Networks, 2009. ICTON '09 (pp. 1-4). IEEE.

https://doi.org/10.1109/ICTON.2009.5185025

\section{General rights}

Copyright and moral rights for the publications made accessible in the public portal are retained by the authors and/or other copyright owners and it is a condition of accessing publications that users recognise and abide by the legal requirements associated with these rights.

- Users may download and print one copy of any publication from the public portal for the purpose of private study or research.

- You may not further distribute the material or use it for any profit-making activity or commercial gain

- You may freely distribute the URL identifying the publication in the public portal

If you believe that this document breaches copyright please contact us providing details, and we will remove access to the work immediately and investigate your claim. 


\title{
Vectorial Analysis of Dielectric Photonic Crystal VCSEL
}

\author{
Il-Sug Chung and Jesper Moerk \\ Technical University of Denmark, DK-2800 Kgs. Lyngby, Denmark \\ Tel: (45) 4525 6383, e-mail: ilch@fotonik.dtu.dk
}

\begin{abstract}
A new vertical-cavity surface-emitting laser structure employing a dielectric photonic crystal mirror has been suggested and been numerically investigated. The new structure has a smaller threshold gain, a moderate strength of single-transverse-mode operation, a high quality of emission beam free from the scattering, and a potential of considerably increasing the single-mode output power.
\end{abstract}

Keywords: single-mode, high power.

\section{INTRODUCTION}

Single-transverse-mode operation, high output power, and polarization stability of vertical-cavity surfaceemitting lasers (VCSELs) are of high importance for applications of high-performance optical communication. Employing photonic crystal $(\mathrm{PhC})$ in a top distributed Bragg reflector (DBR) of VCSEL for transverse confinement is one of promising approaches to potentially achieve all these features [1]-[7]. Many investigations have been performed to understand the fundamental physics and to find optimal designs of PhC VCSELs. However, large optical loss due to deeply-etched air holes still remains as a problem. The large optical loss is undesirable because it increases not only threshold current but also operating current level. High operating current can limit maximum single-mode output power via heating problem and lead to higher electrical power consumption.

In this paper, a PhC VCSEL structure based on a dielectric mirror is suggested to considerably reduce optical loss without any expense of single-mode property. It is discussed that the good single

\section{DEVICE STRUCTURE AND SIMULATION METHOD}

\subsection{Device Structure}
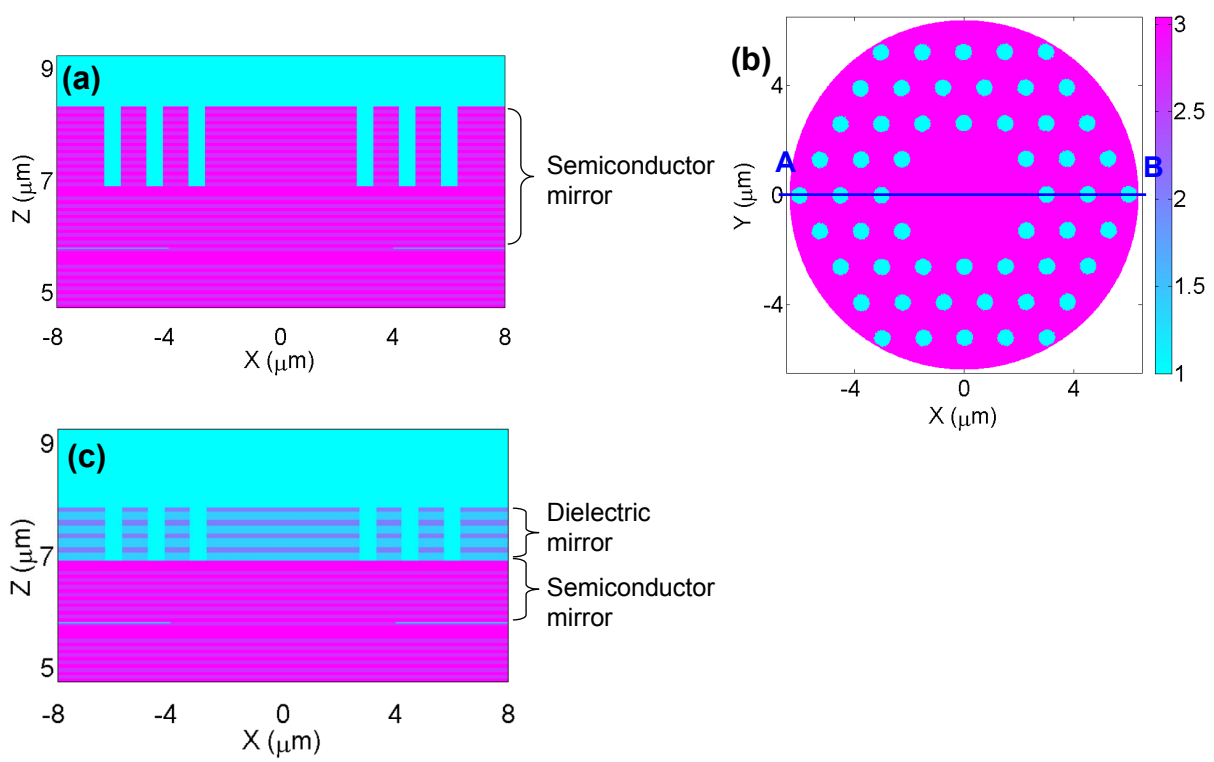

Figure 1. (a) Cross-sectional and (b) top views of the refractive index profile of the investigated semiconductor PhC VCSEL. (b)Cross-sectional refractive index profile of the dielectric PhC VCSEL.

Two PhC VCSEL structures and a reference plain VCSEL structure are investigated. In the structure of Fig. 1(a), hereafter called 'semiconductor PhC VCSEL', the top DBR is composed of 19 pairs of $\mathrm{Al}_{0.12} \mathrm{Ga}_{0.88} \mathrm{As} / \mathrm{Al}_{0.9} \mathrm{Ga}_{0.1}$ As layers. Triangular-lattice air holes with $1.5 \mu \mathrm{m}$ lattice constant and $600 \mathrm{~nm}$ hole diameter are formed in the upper 11 pairs. Seven air holes are missed off the center to make a defect region, as shown in Fig. 1(b). The reflectivity of un-patterned top DBR (19 pairs) is $99.63 \%$. In the structure of Fig. 1(b), hereafter called 'dielectric PhC VCSEL', the top DBR is made of 4 pairs of $\mathrm{TiO}_{2} / \mathrm{SiO}_{2}$ layers and 8 pairs of $\mathrm{Al}_{0.12} \mathrm{Ga}_{0.88} \mathrm{As} / \mathrm{Al}_{0.9} \mathrm{Ga}_{0.1}$ As layers. Its un-patterned reflectivity is $99.69 \%$. Same air holes as in semiconductor $\mathrm{PhC}$ VCSEL are formed only in $\mathrm{TiO}_{2} / \mathrm{SiO}_{2}$ layers. In both devices, the active region has three $7 \mathrm{~nm}$ thick GaAs/AlGaAs QWs in a 1- $\lambda$-cavity, the bottom DBR consists of 40 pairs of $\mathrm{Al}_{0.12} \mathrm{Ga}_{0.88} \mathrm{As} / \mathrm{Al}_{0.9} \mathrm{Ga}_{0.1} \mathrm{As}$ layers, 
and an $8 \mu \mathrm{m}$ diameter oxide aperture is situated near a node position of longitudinal standing wave. Thus, the mode confinement is mainly determined by the $\mathrm{PhC}$ air holes. The resonance wavelength is about $850 \mathrm{~nm}$.

\subsection{Simulation Method}

A 3D vectorial optical VCSEL simulator based on modal expansion and coupled mode theory [8] is used to analyze the properties of the different cavity structures. The reliability of this approach has been verified in simulations of various VCSEL structures [9]-[11], showing good agreements with experimental results. The advantage of modal expansion approach over standard vectorial methods based on spatial grid such as finite element method (FEM) and finite-difference time-domain method (FDTD) is its higher speed with less memory requirement. For example, our modal expansion code takes a few seconds to 5 hours with $0.1-2$ GB memory on a $3.0 \mathrm{GHz}$ Core2Duo processor to find a mode, while FEM needs 10 - 30 hours with 20 - 50 GB memory on a $2.4 \mathrm{GHz}$ Opteron processor [12].

The single mode property is characterized in terms of the mode stability factor $S$ instead of the side-mode suppression-ratio (SMSR). The mode stability factor is a commonly used parameter in optical simulations of VCSELs; it is defined as:

$$
S=\left(g_{1}-g_{0}\right) / g_{0} \times 100(\%),
$$

where $\mathrm{g}_{0}$ and $\mathrm{g}_{1}$ are the threshold material gains of the fundamental and first order modes, respectively. For reference, the surface relief VCSEL, a state-of-the-art single mode device, has $S$ values of $55-85 \%$ that typically correspond to a $30 \mathrm{~dB}$ SMSR, when its oxide aperture is $8 \mu \mathrm{m}$.

Hardley's effective index model is used only for calculating effective index profile [13].

\section{Results and Discussion}

All the simulation results are summarized in the Table 1.

\subsection{Scattering Loss}

Employing a dielectric $\mathrm{PhC}$ mirror instead of a semiconductor $\mathrm{PhC}$ mirror reduces the $\mathrm{g}_{0}$ value by a half. This is because the smaller index difference of the dielectric mirror $(n=2.29 / 1.48)$ from the air hole $(n=1)$ than that of the semiconductor mirror $(n=3.54 / 3.04)$, results in a much smaller scattering loss. In the field intensity profiles of Fig. 2, much stronger scattered field is observed in the semiconductor PhC VCSEL case, both for the fundamental and first order modes.

In the dielectric VCSEL case, most of scattered field is emitted through the bottom DBR. The larger index contrast of the dielectric mirror $(\Delta n \sim 0.81)$ results in high reflectivity that is less insensitive to the incident angles. This characteristic improves the beam quality of top emission, considerably.

\subsection{Single-mode Strength}

Using a dielectric PhC mirror drops also the $S$ value. However, the $\mathrm{S}$ value of the dielectric PhC VCSEL, i.e. $57 \%$ still can provide a stable single mode operation, as compared to the $S$ value of the surface relief VCSEL which ranges from 55 to $85 \%$.

Table 1. Result Summary.

\begin{tabular}{|c|c|c|}
\hline Measured quantity & Semi. PhC VCSEL & Diel. PhC VCSEL \\
\hline Threshold gain, $g_{0}$ & $2403\left(\mathrm{~cm}^{-1}\right)$ & $1224\left(\mathrm{~cm}^{-1}\right)$ \\
\hline Stability factor, $S$ & $137(\%)$ & $57(\%)$ \\
\hline $1 / \mathrm{e}^{2}$ Mode size & $5.02(\mu \mathrm{m})$ & $6.22(\mu \mathrm{m})$ \\
\hline $1 / \mathrm{e}^{2}$ Far-field angle & $10.3($ degree $)$ & $11.0($ degree $)$ \\
\hline
\end{tabular}

\subsection{Mode Size \& Far Field Angle}

The mode size can be increased using the dielectric PhC. As shown in Fig. 3, the air holes of the semiconductor $\mathrm{PhC}$ leads to large effective index difference $\Delta n_{\text {eff }}$ of 0.050 , and the mode size is determined mainly by the air holes. But, in dielectric PhC VCSEL, $\Delta n_{\text {eff }}$ due to air holes is 0.007 as small as $\Delta n_{\text {eff }}$ due to oxide aperture. Thus, the mode size is determined both by air holes and by oxide aperture. Thus, the shallow index contrast in the dielectric PhC VCSEL structure can result in a larger mode size.

The larger mode size results in smaller far-field angle.

\subsection{Single-Mode Output Power}

Most importantly, the 50\% larger modal area of the dielectric PhC VCSEL structure has the potential of considerably increasing the single-mode output power. The record value of single-mode output power from $\mathrm{GaAs} / \mathrm{AlGaAs} \mathrm{QWs}$ is 6-7 $\mathrm{mW}$. 

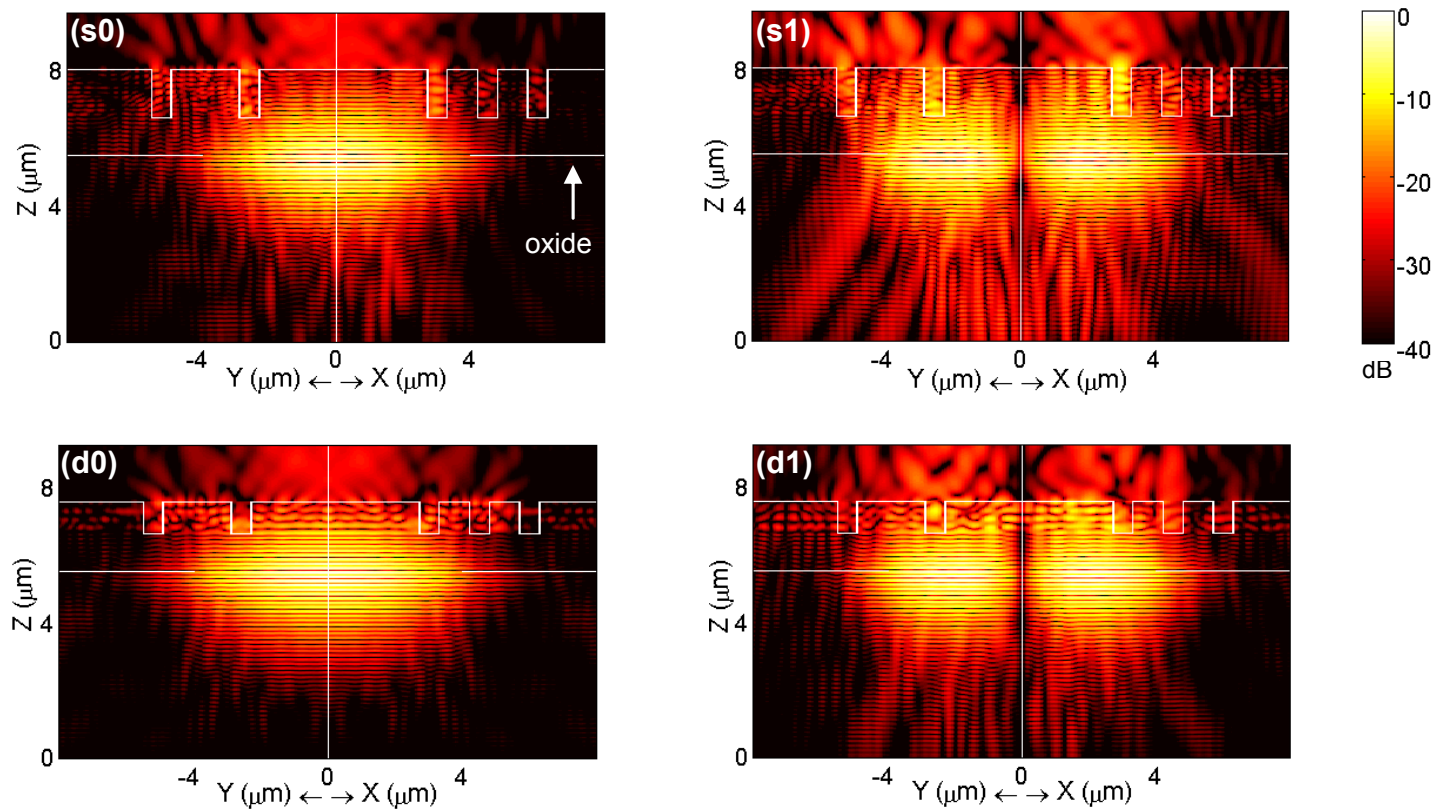

Figure 2. (s0, s1) X-and Y-cut cross-sectional intensity profiles of (s0, s1) fundamental and first order modes of semiconductor PhC VCSEL, and (d0, d1) those of dielectric PhC VCSEL. The intensity is normalized with respect to the peak intensity value at the active region, and is measured in $\mathrm{dB}$ scale.

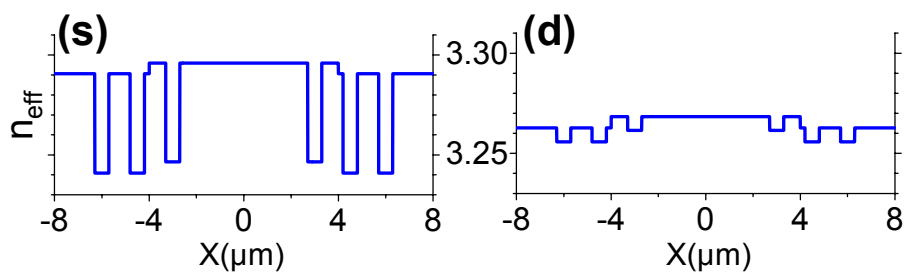

Figure 3. Effective index profiles of (s) semiconductor and (d) dielectric PhC VCSELs, obtained by effective index model [13].

\section{CONCLUSIONS}

A new high-power single-mode vertical-cavity surface-emitting laser structure employing a dielectric photonic crystal mirror has been suggested. Rigorous numerical investigations show that the new structure can have many good characteristics; small threshold gain, good beam quality, and high single-mode output power.

\section{ACKNOWLEDGEMENTS}

This work has been supported by EU IST-FP6 through the MOSEL project and by FTP grant of the Danish Research Council (Sagsnr: 274-08-0361).

\section{REFERENCES}

[1] D. Zhou and L. J. Mawst: High-power single-mode antiresonant reflecting optical waveguide-type verticalcavity surface-emitting lasers, IEEE J. Quantum Electron., vol. 38, no. 12, pp. 1599-1601, Dec. 2002.

[2] Å, Haglund, J. S. Gustavsson, J. Vukušić, P. Modh, and A. Larsson: Single fundamental-mode output power exceeding $6 \mathrm{~mW}$ from VCSELs with a shallow surface relief, IEEE Photonic. Technol. Lett., vol. 16, no. 2, pp. 368-370, Feb. 2004.

[3] R. M. Würtemberg, P. Sundgren, J. Berggren, and M. Hammer: $1.3 \mu \mathrm{m}$ InGaAs vertical-cavity surfaceemitting lasers with mode filter for single mode operation," Appl., Phys. Lett., vol. 85, no. 21, pp. 48514853, Nov. 2004. 
[4] A. Furukawa, S. Sasaki, M. Hoshi, A. Matsuzono, K. Moritoh, T. Baba: High-power single-mode verticalcavity surface-emitting lasers with triangular holey structure, Appl., Phys. Lett., vol. 85, no. 22, pp. 51615163, Nov. 2004.

[5] W. Jiang, J. Ramdani, and M. S. Lebby: Vertical cavity surface emitting laser for high power single mode operations has an extended cavity structure promoting high modal loss, U.S. patent, US6026111-A

[6] M. C. Y. Huang, Y. Zhou, C. J. Chang-Hasnain: A surface-emitting laser incorporating a high-indexcontrast subwavelength grating, Nature photonics, vol. 1, pp. 119-122, Feb. 2007.

[7] V. Jayaraman, M. Mehta, A. W. Jackson, S. Wu, Y. Okuno, J. Piprek, and J. E. Bowers: High-power 1320nm wafer-bonded VCSELs with tunnel junctions, IEEE Photonic. Technol. Lett., vol. 15, no. 11, pp. $1495-$ 1497, Nov. 2003.

[8] G. B. Bava, P. Debernardi, and L. Fratta: Three-dimensional model for vectorial fields in vertical-cavity surface-emitting lasers, Phys. Rev. A, vol. 63, p. 023816, Jan. 2006.

[9] P. Bienstman et al.: Comparison of optical VCSEL models on the simulation of oxide-confined devices, IEEE J. Quant. Electron., vol. 37, no. 12, pp. 1618-1631, Dec. 2001.

[10] P. Debernardi, J. M. Ostermann, M. Feneberg, C. Jalics, and R. Michalzik: Reliable polarization control of VCSELs through monolithically integrated surface gratings: a comparative theoretical and experimental study, IEEE J. Sel. Top. Quant., vol. 11, no. 1, pp. 1-10, Jan. 2005.

[11] P. Debernardi, B. Kögel, K. Zogal, P. Meissner, M. Maute, M. Ortsiefer, G. Böhm, and M.-C. Amann: Modal properties of long-wavelength tunable MEMS-VCSELs with curved mirrors: comparison of experiment and modeling, IEEE J. Quant. Electron., vol. 44, no. 4, pp. 391-399, Apr. 2008.

[12] P. Nyakas: Full-vectorial three-dimensional finite element optical simulation of vertical-cavity surfaceemitting lasers, J. Lightwave Technol., vol. 25, no. 9, pp. 2427-2434, Sep. 2007.

[13] G. R. Hardley: Effective index model for vertical-cavity surface-emitting lasers, Opt. Lett., vol. 20, pp. 1483-1485, 1995. 